\title{
The use of software in Biochemistry teaching classes
}

Maiara Dias Büttenbender ${ }^{1}$, Bruna Piaia Ramborger ${ }^{1}$, Anderson da Silva Rosa ${ }^{1}$, Rafael Roehrs ${ }^{1}$

1 Universidade Federal do Pampa, Rio Grande do Sul, Brazil

INTRODUCTION: The rising of new technologies meant to improve education could be considered a high advance to pedagogic methodologies. Software is defined as computer programs and may be considered educative when they present a methodology which assists and contextualizes the teaching-learning process. Specifically regarding Biochemistry, a knowledge area which explains physiological and pathological phenomena that occur in human beings, applying the use of software would turn out an easy way to observe such phenomena. MATERIAL AND METHODS: In order to carry out this work, two free software designed to be used in Biochemistry area and developed at Universidade Estadual de Campinas ("Síntese Proteica" (Protein Synthesis) and "A cinética da reação enzimática" (Kinetics of enzymatic reaction)), were compared. Interface, how to work contents, advantages and disadvantages in the use of such kind of technology inside classroom were some of the evaluated parameters. DISCUSSION AND RESULTS: Both programs present a fine graphic design, allowing easy command comprehension. At the beginning the objectives of the programs and the contents they hold are presented, showing also a brief introduction to the topic. The programs also present instruction manuals that explain how the experiments work. They are small basic and simple programs that run easily where they are placed, not needing internet access after their download. "Kinetics of enzymatic reaction" presented more interactive options than the other, and its operation could be considered more intuitive. CONCLUSION: We considered "Kinetics of enzymatic reaction" a better software, cause it allows the student to observe the experiment and perform the calculations proposed, improving the learning process in a significantly way. The use of new technologies inside classrooms should be encouraged as a way to attract the attention and interest of students, since they are used to interact with computer and internet in their day-today activities. There are several kinds of software which could assist teachers and students in the teaching-learning process; however it is very important to evaluate the capacities of such software before using it, making sure to choose the right one.

Keyword: Biochemistry, softwares, new technologies. 